\title{
Relationship Between Categories of Masculinities and Incidences of Family Crises in Modern Family:A Case of Selected Faith-Based Organisations in Bahati Sub-County, Nakuru County, Kenya
}

\author{
Samwel Kiuguini Nduati ${ }^{*} \quad$ Ruth Aura $^{2} \quad$ Damaris Parsitau $^{1} \quad$ Stephen Ngari Mbugua $^{3}$ \\ 1.Institute of Women, Gender and Development Studies, Egerton University, PO box 536 - 20115, Egerton \\ 2.Faculty of Law, Egerton University, PO box 536 - 20115, Egerton \\ 3.Catholic University of East Africa, PO box 62157 - 00200, Nairobi, Kenya
}

\begin{abstract}
Globally, the modern family is faced by incidences of family crises which include Gender Based Violence (GBV), separation and divorce, alcohol and substance abuse, neglect of family responsibilities and mental breakdown. While numerous suggestions have been offered as to why this is the case, a growing body of literature links negative masculinities with the incidences of family crises. In response to this, some Faith-Based Organisations (FBOs) have begun working with men as a way of transforming masculinities. This study used Kenya Anglican Men Association (KAMA) and Presbyterian Church Men Fellowship (PCMF) as selected FBOs to explore the relationship between categories of masculinities and incidences of family crises in Bahati Sub-County, Nakuru County. The study was guided by Connell theory of masculinity which conceives that the relationships among male individuals consist of four categories of masculinity: hegemonic, subordinate, complicit and marginalized. Stratified random sampling procedure was used to obtain a total sample size of 209 participants. Data was collected through a questionnaire, interviews and Focused Group Discussion (FGD) schedules. Descriptive and inferential statistics, specifically ordered logistic regression were used for analysis, with the help of Statistical Package for Social Sciences (SPSS) version 20 for windows. Descriptive statistics included frequency tables, charts and mean scores. Findings of the study established that categories of masculinities have a positive and significant relationship with incidences of family crises. In this regard the study recommends that there is need of transforming masculinities especially by FBOs, institutions of learning and family.
\end{abstract}

Keywords: Categories of Masculinities, Family crises, Modern family, Faith-Based Organisations, KAMA, PCMF.

DOI: $10.7176 /$ RHSS/10-4-07

Publication date: February $29^{\text {th }} 2020$

\section{Introduction}

Families play a central role in societies as they are the primary site for reproduction, socializing the next generation, early education, and stabilizing adult personality formation. The modern family refers to the family unit where marriage landscape is changing due to rise in divorce, remarriage, single parenthood, civil partnerships and reconstituted families (Stevenson \& Wolfers, 2007). In this study it refers to the family unit in transition from the traditional family to the modern family set up. This family is "modern" in the sense of "modernisation" which is commonly interpreted through formal education, European Christianity, urbanisation, and industrialisation (Oheneba-Sakyi and Takyi, 2006). This modern family has its composition different from traditional rural societies which had extended family systems including generations of cousins, uncles and aunts living close to one another (Kimani \& Kombo, 2010). Globally, the modern family is faced by incidences of family crises which include Gender Based Violence (GBV), separation and divorce, alcohol and substance abuse, neglect of family responsibilities and mental breakdown.

While numerous suggestions have been offered as to why we have incidences of family crises, a growing body of literature links negative masculinities with why this is the case. Masculinity can be defined as a set of behavioural patterns that men ought to follow in each given society (Chitando \& Chirongoma, 2012). GormanMurray and Hopkins (2014) emphasis that one is not born but becomes a man or a woman, and normative gender roles and performances are acquired through socialisation within the context of institutions such as the family, school, media and workplace. In this regard it can be observed that masculinities emphasizes gender, not biological sex, and the diversity of identities among different groups of men. There is general acceptance of the plural "masculinities" rather than singular "masculinity" because research has shown that in fact there are different ways of being a man (Van Klinken \& Smit, 2013).

In response to the incidences of family crises facing the modern family, some Faith Based Organisations (FBOs) have begun working with men in transforming masculinities. Kenya Anglican Men Association (KAMA) and Presbyterian Church Men Fellowship (PCMF) in Bahati Sub-County, Nakuru County are some of the FBOs which are transforming negative masculinities in order to have positive masculinities characterized by being caring, 
less violent, respectful to women and acceptance of family responsibilities.

A growing body of literature links negative masculinities with the incidences of family crises. However there is no research which has been conducted in Kenya among Faith-Based Organiations to find out the relationship between categories of masculinities and incidences of family crises. Therefore there is need to conduct research to find out how hegemonic, subordinate, marginalised and complicit masculinities are related to incidences of family crises. In this regard, this study sought to find out the relationship between categories of masculinities and incidences of family crises in Kenya Anglican Men Association (KAMA) and Presbyterian Church Men Fellowship (PCMF) in Bahati Sub-County, Kenya.

\subsection{Research Objectives \\ i. To document the incidences of family crises facing the modern family in Bahati Sub-County, Nakuru County \\ ii. To determine the relationship between categories of masculinities and incidences of family crises in Bahati sub-county.}

\subsection{Research Question}

What are the incidences of family crises that are facing the modern family in Bahai Sub-County, Nakuru County, Kenya?

\subsection{Research Hypothesis (Ho)}

There is no statistically significant association between categories of masculinities and incidences of family crises in Bahati Sub-county, Nakuru County.

\section{Literature Review}

According to Guedes, Bott, Garcia-Moreno and Colombini (2016), modern family faced by family crises which include, Gender Based Violence (GBV), separation and divorce, alcohol and substance abuse, neglect of family responsibilities and lack of mentorship to the children. Victims of GBV regardless of geographical and cultural differences, are mostly children and women rather than men. This study focused on GBV against women by their husband or male partner who practice negative masculinity. Other kinds of domestic violence, though related to the incidences of family crises such as violence against men or children, were beyond the scope of this study.

Worldwide, almost one third (30\%) of all women who have been in a relationship have experienced physical and/or sexual violence by their intimate partner (Muñoz-Boudet, Petesch, \& Turk, 2013). Also "some national violence studies show that up to 70 per cent of women have experienced physical and/or sexual violence in their lifetime from an intimate partner" (Bonomi, Anderson, Rivara \& Thompson (2007). This has led to the phenomena of marital breakdown, the increase in lone parent households, the rise in blended and step families, the increase in same-sex families with children, the incidence of domestic violence, and the challenge of disability or illness in the family (Fulu, \& Miedema, 2015).

Across Sub-Sahara Africa, reports of prevalence and incidence of GBV have been reported (Roman \& Frantz, 2013). In Zambia, the problem of violence against women is worrisome and GBV is considered not an isolated problem or a side component of people's life, but a widespread, tragic and daily issue that touches and impacts every Zambian in one way or the other (Morel-Seytoux, Liveoak, Mwansa, Prieto, Thompson, 2010). In Zimbabwe, domestic violence has been described as a sensitive, harrowing community issue that affects one in three women with many women still finding themselves in a position where they are vulnerable to all forms of violence despite legislation to prevent domestic violence (De Wet, 2009). At least, $60 \%$ of the murder cases brought before the Zimbabwe High Court are a direct result of domestic violence (Chitukutuku, 2017). In Nigeria, the largest country in Africa, several studies have reported high prevalence of violence against women especially from spouse or intimate partner (Oyediran, \& Isiugo-Abanihe, 2005; Antai \& Antai, 2008).

Kenya also experience incidences of family crises. Gender Based Violence is one of them. The report by National Gender and Equality Commission (2016) on Gender Based Violence in Kenya demonstrated that GBV is perhaps the most widespread and socially tolerated human rights violation in Kenya. According to Mwakio (2015) GBV is any physical, sexual or psychological violence that occurs within the family or general community, 43 percent of married women have experienced sexual violence. Mwakio (2015) reveals that women who are divorced, separated or widowed are more likely to be exposed to violence (at $60 \%$ ) than their married (at $42 \%$ ) and never-married (at 25\%) counterparts. Some of the causes associated with GBV include increasing poverty, women dependency on men for livelihood, pornography, rising cases of child headed households, alcoholism, drugs and drugs abuse, children watching intimate moments between adults/parents that encourages children to have early sex or child to child sex (Jewkes, Flood \& Lang, 2015).

Divorce is another incidence of family crises facing the modern family in Kenya. Kimuna and Djamba (2008) assert that there was a gradual increase in divorce cases in Kenya. A study carried out between 2001 and 2014 
revealed as follows: "In 2001, a total of 101 divorce cases were filed at Milimani Law Courts. The number rose to 115 in 2002 and then 206 cases in 2003. The following years 2004, 2005, 2007 and 2008 recorded 296, 295, 357 and 369 cases respectively. Between 2010 and 2015, a total of 1,246 cases have been filed" (Muthoni \& Makana, 2015). Muthoni and Makana (2015) assert that divorce and separation are on the rise in Kenya. They further claim that if a woman is in her early 40s today, she was aged 20 and 24 years in 1998 and at that time just 34 per cent of her peers were divorced or separated. According to Durevall and Lindskog (2015), six percent of women aged 2024 have already divorced or separated, a proportion almost double from two decades ago.

Negative masculinities have been linked to the incidences of family crises facing the modern family. There is general acceptance of the plural "masculinities" rather than singular "masculinity" because research has shown that in fact there are different ways of being a man (Van Klinken \& Smit, 2013). Recent research reveals that rather than being one single masculinity, there exist several different ways of being masculine (Connell, \& Messerschmidt, 2005). Connell, and Messerschmidt (2005) identified four different types of masculinity: hegemonic, subordinate, complacent and marginal.

Hegemonic masculinity is the form embodying male domination and exercising power and authority over women (and other men), with all the consequences of oppression, violence and privileges. Hegemonic masculinity represents the traditional archetype of virility and male stereotypes in accordance with a patriarchal culture. This concept of hegemony, derived from Gramsci's analysis of class relationships, refers to the cultural dynamic through which one group demands and maintains a position of leadership in social life. At any given time, one form of masculinity is prized culturally over others. Hence, hegemonic masculinity is defined as a configuration of generic practices that embody the currently accepted response to the problem of the legitimacy of patriarchal attitudes, guaranteeing the dominant position of men and the subordination of women. Hegemonic masculinity has been historically conceived as a form of status that includes toughness, aggressiveness, stoicism and sexuality (Mankowski \& Maton, 2010). Clatterbaugh (2018) point out that there is always in each society a hegemonic masculinity, which dominates not only women but also other masculinities. According to Jewkes and Morrell (2012) hegemonic masculinity is a set of values, established by men in power that functions to include and exclude, and to organize society in gender unequal ways. It combines several features: a hierarchy of masculinities, differential access among men to power (over women and other men), and the interplay between men's identity, men's ideals, interactions, power, and patriarchy (Jewkes and Morrell, 2012). Hegemonic masculinity is connected to the destructive masculinity rooted in centuries of old supremacy, patriarchy and oppression played through such events as slavery, colonisation and war (Sweeney, 2014)). This leads to violence, passion killing, alcoholism, dangerous driving, rape, political violence and spread of HIV.

Subordinate masculinity is found on the fringes of traditional lifestyles, with behaviors and feelings conventionally attributed to women, so that it is considered inappropriate and effeminate by most men. This type of masculinity would comprise both male behaviors of a homosexual orientation and some other ways of being a man closer to the values normally seen as typical of women (a caring ethos towards people, an emphasis on feelings and emotions, solidarity with feminist stances and the like). Subordinate masculinity exhibit qualities that are opposite of those values in hegemonic masculinity and may exhibit physical weakness or be very expressive with emotions (Frisina, 2018).

According to Connell and Messerschmidt, (2005), marginalised masculinity refers to those groups of men who suffer social exclusion and have only very limited access to power (for instance, the black minority in the United States, North African immigrants in Europe, or indigenous tribes in Latin America). They are at the receiving end of all sorts of injustice and oppression in societies led by men who shamelessly exercise the most tyrannical and unjust forms of hegemonic masculinity. Despite this, they do not question male domination nor its behavior patterns (especially those referring to relationships with women), nor do they distance themselves in any significant fashion from the misogynistic and violent tone adopted by patriarchal culture (Kennedy, 2016).

Finally complacent masculinity is the category relating to men who have no significant access to power and lack any high financial or social status, but still enjoy the patriarchal dividends associated with the male sex, without ever questioning the justice of such privileges. According to Howson (2006), the vast mass of men have little or no direct connection with either hegemonic, subordinate or marginalised masculinities, that is, they cannot or do not actively seek to embody these ideals into their gender practice. Nevertheless, this same mass of men gain advantage and privilege by accepting, albeit a priori, the existence of a benchmark against which they can position themselves in relation to its symbolised ideals (Howson, 2006). Complicit masculinities are often seen as lesser versions of the hegemonic ideal because their advantage is never as clear-cut, and is often made without the tensions or risks that being on the frontline of the system brings (Connell 1995): Complacent masculinity is no more than an attenuated version of standard masculinity and a visible tip of the iceberg of hidden machismo (Fernández-Álvarez, 2014).

There is a connection between masculinities and incidences of family crises facing the modern family. For instance in connection to violence Mansley (2009) stated that men are violent to intimate partners due to their gender-role socialization, distorted gender-role schemas, gender-role conflicts, defense mechanisms, and self- 
protective defense strategies.

\subsection{Theoretical Framework}

This study was based on Connell theory of masculinity. This theory argues that a hierarchal system exists within the category of masculinity (and femininity). (Conell, 2009). The concept of hegemonic masculinity is clearly the most popular and influential element of Connell's theory of masculinity (Wedgwood, 2009). It is part of Connell's gender order which recognizes multiple masculinities that vary across time, culture and the individual. This theoretical model proposed by the sociologist Connell conceives that the relationships among male individuals consist of four categories of masculinity: hegemony, subordination, complicity and marginalization. This plurality of masculinity is brought about by masculinity being associated with culture. There is much masculinity as there are cultures, classes, times and places and their contours change over time (Morrell, 2001). Hegemonic masculinity is defined as the current configuration of practice that legitimizes men's dominant position in society and justifies the subordination of women and other marginalized ways of being a man (Connell, 2005). Connell's theory of masculinity also recognizes masculinity as a social construct. So masculinity is a gendered identity and therefore excluded from categories of nature and biological determinism (Leshota, 2013). But men are susceptible to change (Morrell, 2001).

\section{Research methodology}

The study was carried out in Bahati sub-county which is located in the greater Nakuru County. Bahati sub-county was selected because of its uniqueness as it is characterized by various ethnic communities, in which religious beliefs, social norms and cultural values provide a framework within which men participate in doctrine trainings especially in the two mainstream churches (PCEA and ACK) training. The study used ex post- facto research design which is appropriate to behavioral science because the independent variable cannot be manipulated (Orodho, 2003). Ex post -facto research design is a system of empirical inquiry in which, the researcher does not have direct control of independent variables because their manifestations have already occurred. Purposive sampling procedure was used to select 928 registered members in the Faith-Based organizations (KAMA \&PCMF) in the sub-county. The formula by Creswell (2014) was used to determine the actual sample size for the study.

$$
n=\frac{N C^{2}}{C^{2}+(N-1) e^{2}}
$$

Where:

$\mathrm{n}=$ Sample size, $\mathrm{N}=$ Population, $\mathrm{C}=$ Coefficient of variation, $\mathrm{e}=$ Standard error

$\mathrm{C}=30 \%$ was acceptable according to Creswell (2007) $\mathrm{e}=0.02$ and $\mathrm{N}=928$.

$$
n=\frac{928 \times 0.3^{2}}{0.3^{2}+(928-1) 0.02^{2}}=181.25
$$

Therefore, 181 men respondents formed the sample size for the study. From the 14 Churches all the clergy who were both male and female were included in the study as key informants. In addition two Focused Group Discussions (FGDs) comprising of lay leaders were conducted. One FGD was conducted in KAMA and the other one in PCMF. The number of all participants in the FGDs was 14. Therefore the total sample size comprised 209 participants. To ensure equal representation of each category of Faith-Based organizations, stratified random sampling was used to select the respondents for the study. The starting point in applying the stratified random sampling was to determine the number of eligible participants in the study. The population was then divided into constituent subgroups (strata) according to Faith-Based organization (KAMA \&PCMF) and the subjects were selected from each subgroup using random sampling through the lottery technique. The target population was arranged sequentially and assigned identification corresponding numbers which was marked on separate tabs and put into a container. The numbers were tossed so that they were thoroughly mixed. Then one tab bearing a number was selected from the container, without the researcher seeing it until the required sample size was selected. This ensured that every individual had the same chance of being chosen. According to Creswell (2014) lottery technique is applied to ensure that the sample selection is independent of human judgment.

In this study questionnaires, interview schedules and Focused Group Discussion Guide (FGD) guide were used for data collection. Questionnaires were administered on a face to face basis to collect baseline data from the eligible men members registered in the two Faith-Based Organization. This was appropriate since questionnaires are used to collect basic descriptive information from a broad sample (Creswell, 2014). Each item in the questionnaire was developed to address specific research objectives. The questionnaire was designed with closed and open ended items to capture interval, ordinal and nominal data. To clarify and confirm data gathered using the questionnaire, key informants interview and two FGDs were conducted. Interview schedule was used to collect data during the key informants interview. The key informants were 14 clergy, both male and female, who were 
priests in charge of the 14 selected Churches in Bahati sub-county. They were chosen because thy held key information about the FBOs under their care. FGD guide was used to collect data during the discussions with lay leaders of the two FBOs. The lay leaders are charged with management of the activities of FBOs.

\section{Research Findings and Discussions}

The first objective of the study was to document the incidences of family crises facing the modern family in Bahati Sub-County, Nakuru County The study inquired from the respondents how they could describe the incidences of family crises in modern family. From the literature review the incidences of family crises facing the modern family were identified as, Gender Based Violence (GBV), separation and divorce, alcohol and substance abuse, neglect of family responsibilities and mental breakdown. These are the crises which were used in the study. The respondents were asked to rate their agreement on the incidences of family crises on a score of 1 to 5 (1=Strongly disagree, $2=$ Disagree, $3=$ Undecided, $4=$ Agree, $5=$ Strongly agree).Table 1 shows the summary of the responses given by the respondents on the incidences of family crises.

Table 1: Incidences of Family Crises Facing the Modern Family

\begin{tabular}{|c|c|c|c|c|c|}
\hline Characteristic & $\mathrm{SA}$ & A & $\mathbf{U}$ & D & SD \\
\hline Gender Based Violence & $28 \%$ & $62 \%$ & $2 \%$ & $5 \%$ & $4 \% \%$ \\
\hline Separation and Divorce & $30 \%$ & $54 \%$ & $4 \%$ & $12 \%$ & $2 \% \%$ \\
\hline Alcohol drugs and Substance Abuse & $33 \%$ & $56 \%$ & $2 \%$ & $9 \%$ & - \\
\hline Neglect of Family Responsibilities & $20 \%$ & $61 \%$ & $6 \%$ & $10 \%$ & $2 \%$ \\
\hline Mental Breakdown & $9 \%$ & $39 \%$ & $17 \%$ & $26 \%$ & $9 \%$ \\
\hline
\end{tabular}

The results showed that a big proportion (90\%) of the respondents identified positively that there is GBV in the modern family which means that only $9 \%$ who did not identify GBV as one of the incidences facing the modern family. From the interviews conducted with the clergy, all the respondents agreed that in their work in the Church they have observed GBV among some Christian families. One male key informant/clergy who was interviewed explained:

"There is Gender Based Violence in the Church as well. Men threaten to beat their wives. They even do it, and they come to Church. This is due to dysfunction in the modern family where women seem to defy the authority of men and on the other hand men want to maintain their position of authority. But the greatest problem is that men have taken back seat where women have now become leaders in their homes which should not be the case. It is unbiblical! This is why men and women are fighting"

The Focused Group Discussion revealed that men are also facing GBV from their wives. One respondent from the FGD conducted with KAMA leaders had the following to say:

"Men are suffering from verbal Gender Based Violence. Wives do not respect their husbands when they are poor. In fact Rev, these women use verbal insults even in the presence of the children."

Also from the interview schedule conducted for the key informants/clergy, one female key informant (the clergy were both male and female) exclaimed:

"I really feel for the men today. You cannot imagine that many of them in my church disclose to me about their sufferings. They find it very easy to open up to me, because I am a female clergy. I have a case where a wife has stopped to serve her husband. Ok, she is a business lady and the husband is a teacher, but after she comes back home, she cooks her meal, washes dishes and sits to watch the T.V unconcerned about the husband. When he comes back home from work he finds no food. Due to that and many other issues he has become sick and always carries medicine in his pocket."

When asked whether the couple still attend Church the respondent explained:

"Yes they do, but the lady cannot come in her husband's vehicle. They also don't come together. She walks and therefore the husband decides to leave the vehicle home to avoid questions from other Church members. He also walks but way behind the wife. You know, they are living under the same roof but they are not together. Is this not the crisis we are talking about?"

This finding relates to Meda (2013) who identified that men are also in a crisis noting that the problem with modern families resides in the crisis of the male; who are at a crossroad in what concerns his identity and role in the family and in the society, at least as much as in the crisis of women. Perhaps more than women they are struggling to find a new dimension and their identity. This implies that transforming masculinities is not only beneficial to women but to men as well.

The results on table 1 , shows that a huge proportion $(84 \%)$ positively identified that there is separation and divorce in the modern family. This result is similar to the observation by Muthoni and Makana (2015) who assert that divorce and separation are on the rise in Kenya. In the interview with the key informants/clergy one male 
clergy had the following to say:

"Divorce is a current major challenge to the Church. It is on the rise! You know, if a woman comes to you as a priest and tells you that she is running away from her husband who is threatening to kill her, in your sound mind you cannot advise her to go back and be killed". This result implies that probably due to incidences of family crises, some Churches are rethinking about the position that marriage is permanent, and "what God has joined together no man should put asunder" (Mark 10:9)

The study also showed that biggest proportion (89\%) of the respondents positively identified that there is alcohol and substance abuse in the modern family (see table 1). This result is in line with the report of United Nations (2018) in its World report on Drugs. According to the United Nations report both young people and the older people are abusing drugs and substances but it is more prevalent with the former. The report by the United Nations show that in Kenya, older people report a higher use of established substances such as khat in different forms (miraa and muguka) and cannabis (bhang and hash-ish), while drugs that have become available in Africa more recently, such as cocaine and heroin, are reported to be used more frequently among those aged 18-24. Among the general population, khat and cannabis remain the two most commonly used substances, with the highest lifetime and past-year use among those aged 25-35. Conversely, the life-time use of cocaine, heroin and prescription drugs is nearly three times higher among people aged 18-24 than among those aged 36 years and older. According to Kimani and Kombo (2010) alcoholism, drugs and substance abuse can lead to absentee fathers. The implication is that this can have a significant contribution to dysfunction in the modern family.

The result on table 1 shows that the greatest proportion $(81.2 \%)$ of the respondents positively identified that there is neglect of family responsibilities in the modern family. This similar to the study results by Kimani and Kombo (2010) who found out that men are used to escaping from families as a cover up of their inadequacies to provide and care for their families, while at the same time looking for excuses to abdicate their family responsibilities. From the Focused Group Discussion men blamed women for the neglect of family responsibilities. One respondent retorted:

"Wives in employment are treating their earnings as their own, while they expect their husbands' earnings to belong to the family. Some of the wives do not disclose to their husbands what they earn. This leads to neglect of family responsibilities". When asked for clarification, this respondent further mentioned; "You see, kama mke wngu atanificha kuhusu mapato yake hata nami nitafanya hivyo tu [if my wife decides to keep her earnings as a secret, I will also do the same]". This result implies that family responsibilities may be neglected because each spouse may decide to use their money without their family in mind.

A big proportion $(47.7 \%)$ of the respondents identified that there is mental breakdown in the modern family. The respondents who felt that there is no mental breakdown in the modern family could have done so, due to the fact that discourse about mental breakdown is rare because of the stigma attached to it. According to World Health Organisation (2018), around 450 million people suffer from mental disorders making mental breakdown among the leading causes of ill-health and disability worldwide. Stigma, discrimination and neglect prevent care and treatment from reaching people with mental disorders (WHO, 2018).

Data from the interview with key informants/clergy showed that women are affected more than men by mental breakdown. One respondent explained: "I have dealt with four cases of mental breakdown in the Church but they are all involving women". This result is in line with the observation made by Western (2013) that women are twice as likely as men to experience depression and approximately $20 \%$ of women are likely to experience depression at some time in their lives.

\subsection{Other Incidences of Family Crises from Interviews and FGDs}

It emerged from the findings of the interview schedule with the key informants/clergy that the modern family is also faced with absentee fatherhood, single motherhood, unemployment and infidelity. When asked to describe incidences of family crises facing the modern family, one of the male clergy explained:

"The modern family is one where man seems to be more absent in the sense that our way of work demands that man be away. Let me start with the Anglican Church as a clergy. Look, I am transferred from one parish to another and my wife is permanently employed in one place. That definitely makes me absent from my family. The same applies to teachers. Currently the Kenyan Government is talking of delocalization."

This finding relates to the research conducted by Kimani and Kombo (2010). From their findings, the major reason for absentee fathers is working away from home.

Concerning single motherhood, one female key informant mentioned that "traditionally it was unheard of, where a child was carrying the mother's name as his or her surname. Today it is very common. Why? Because of the dysfunction in the family. What happens with sons from such families is that they lack mentors and they will perpetuate the dysfunction in their future."

Unemployment was also cited by key informants as an incident facing the modern family. A male key informant/clergy gave a case from his Church where a husband died from depression resulting from him being unable to provide for his family. The respondent explained the case thus: 
"I have a case in my church, where a man was retrenched and then he involved himself in taking alcohol. The wife was employed and she was well groomed. The man became insecure after some time and thought that his wife had an extra marital affair. Now look at the insecure man in the modern world. He became so hostile that he would threaten to kill his wife. This made the wife to run away to her parents. After a short while, the man got ill, taken to hospital and unfortunately he did not survive. What else can be said to be the cause of his death, if not unemployment? The question is, did he die as a married man or not? This explains the modern family."

Infidelity was also identified as an incident of family crisis facing the modern family by a respondent from one of the FGD. He said:

'Let us talk the truth here. 'Kuna mpango wa kando' [we have extra marital affairs] with men in the Church as well. Rev, women are to blame on this. They are not respecting their husbands now a days and therefore men have to seek attention elsewhere”.

A key informant/clergy from the interview schedule mentioned that, "both men and women who are married are involved in extra marital affairs."

The second objective of the study was to determine the relationship between categories of masculinities and incidences of family crises in Bahati sub-county. Accompanying this objective there was the null hypothesis that there is no statistically significant association between categories of masculinities and incidences of family crises in Bahati Sub-county, Nakuru County. Chirongoma and Chitando (2012) define masculinity as set of behaviours that most men are expected to conform to. Connell, and Messerschmidt (2005) identified four different categories of masculinities which are hegemonic, subordinate, complicit and marginal. These are the categories of masculinities that the study sought to determine how they are associated with the crises facing the modern family in Bahati Sub- County. An ordered logistic regression was carried out to determine this relationship and the results are shown on table 2.

Table 2: Summary of the results of ordered logistic Regression on Relationship between Categories of Masculinities and Incidences of Family Crises

\begin{tabular}{crrr}
\hline Type of Masculinity & Chi-Square Value & Logit Co-efficient & P-Value \\
\hline Hegemonic & 11.53 & 0.318 & 0.018 \\
Subordinate & 10.01 & 0.247 & 0.043 \\
Marginalized & 19.81 & 0.463 & 0.000 \\
Complicit & 13.53 & 0.310 & 0.006 \\
\hline
\end{tabular}

\subsection{Hegemonic Masculinity}

An ordered logistic regression was carried out in order to test whether there was significant relationship between hegemonic masculinity and incidences of family crises. Hegemonic masculinity has been historically conceived as a form of status that includes toughness, aggressiveness, stoicism and sexuality (Mankowski \& Maton, 2010). Clatterbaugh (2018) point out that there is always in each society a hegemonic masculinity, which dominates not only women but also other masculinities. The results of the ordinal logistic regression indicated that hegemonic masculinity had a statistically significant relationship with incidences of family crises. The logit coefficient for hegemonic masculinity was positive $(0.318)$ with a $p$ value $=0.018$. This implied that for a one unit increase in hegemonic masculinity, the log odds of being in a higher level of incidences of family crises would increase by 0.318. This meant that higher levels of hegemonic masculinity increased the likelihood of having incidences of family crises.

\subsection{Subordinate masculinity}

Subordinate masculinity exhibit qualities that are opposite of those values in hegemonic masculinity and may exhibit physical weakness or be very expressive with emotions (Frisina, 2018). The results of the ordinal logistic regression showed that subordinate masculinity had a statistically significant relationship with the incidences of family crises facing the modern family. The logit coefficient for subordinate masculinity was positive $(0.247)$ with a $\mathrm{p}$ value $=0.043$. This implied that for a one unit increase in subordinate masculinity, the log odds of being in a higher level of the incidences of family crises would increase by 0.247 . This meant that higher levels of subordinate masculinity increased the likelihood of having incidences of family crises.

\subsection{Marginalised Masculinity}

According to Kennedy (2016), marginal masculinity refers to those groups of men who suffer social exclusion and have only very limited access to power (for instance, the black minority in the United States, North African immigrants in Europe, or indigenous tribes in Latin America).An ordered logistic regression indicated that marginalised masculinity had a statistically significant relationship with the incidences of family crises. The logit coefficient for marginalised masculinity was positive $(0.463)$ with a $p$ value $=0.000$. This implied that for a one 
unit increase in marginalised masculinity, the log odds of being in a higher level of incidences of family crises would increase by 0.463 . This meant that higher levels of marginalised masculinity increased the likelihood of having incidences of family crises.

\subsection{Complicit Masculinity}

According to Connell (2005) complicit masculinity comprises of many men who draw the patriarchal dividend but also respect their wives and mothers, are never violent towards women, do their accustomed share of the housework, bring home the family wage, and can easily convince themselves that feminists must be bra-burning extremists. An ordered logistic regression indicated that complicit masculinity had a statistically significant relationship with incidences of family crises. The logit coefficient for complicit masculinity was positive $(0.310)$ with a $\mathrm{p}$ value $=0.006$. This implied that for a one unit increase in complicit masculinity, the log odds of being in a higher level of family crises would increase by 0.310 . This meant that higher levels of complicit masculinity increased the likelihood of having incidences of family crises.

\section{Conclusion}

The results from this study corroborated other studies in that categories of masculinities have a relationship with incidences of modern family crises facing the modern family. The first objective of the study was to document the incidences of family crises facing the modern family in Bahati Sub-County, Nakuru County, Kenya. From the findings the respondents affirmed that the modern family is faced by Gender Based Violence (GBV), separation and divorce, alcoholism, drugs and substance abuse, neglect of family responsibilities and mental breakdown. The second objective of the study was to determine the relationship between categories of masculinities and incidences of family crises in Bahati sub-county. From the results of ordered logistic regression it was determined that there was a strong relationship between all the categories of masculinities and the incidences of family crises facing the modern family. Therefore the null hypothesis was rejected. To mitigate the incidences of family crises facing the modern family, it is important to target men and include them in the programmes which are aimed at transforming masculinities. Faith-Based Organizations are key in the campaign of transforming masculinities and they need to make it their agenda to support men by arming them with skills, knowledge and confidence to resist negative masculinities. It is also recommended that other institutions like the family and schools, colleges and universities should engage in transforming masculinities.

\section{References}

Antai, D. E. \& Antai, J. B. (2008). Attitudes of women toward intimate partner violence: a study of rural women in Nigeria. Rural \& Remote Health, 8(3).

Bonomi, A. E., Anderson, M. L., Rivara, F. P. \& Thompson, R. S. (2007). Health outcomes in women with physical and sexual intimate partner violence exposure. Journal of Women's Health, 16(7), 987-997.

Chitando, E. \& Chirongoma. (2012). 'Challenging Masculinities: Religious Studies, Men and HIV in Africa', Journal of Constructive Theology, 14/1

Chitukutuku, E. (2017). Rebuilding the liberation war base: materiality and landscapes of violence in Northern Zimbabwe. Journal of Eastern African Studies, 11(1), 133-150.

Clatterbaugh, K. (2018). Contemporary perspectives on masculinity: Men, women, and politics in modern society. United Kingdom. Routledge.

Connell, R. W. (1995). Masculinities. Allen and Unwin. St. Leonards.

Connell, R.W. (2009). Om Genus. Göteborg: Daidalo

Connell, R. W. \& Messerschmidt, J. W. (2005). Hegemonic masculinity: Rethinking the concept. Gender \& society, 19(6), 829-859.

Creswell, J. W. (2014). Research Design: Qualitative, Quantitative and Mixed Methods Approaches (4th ed.). California: sage. Thousand Oaks.

De Wet, N. (2009). Domestic violence and child health outcomes in Zimbabwe. Graduate school, University of the Witwatersrand, Zimbabwe.

Durevall, D. \& Lindskog, A. (2015). Intimate partner violence and HIV in ten sub-Saharan African countries: what do the Demographic and Health Surveys tell us? The Lancet Global Health, 3(1), e34-e43.

Fernández-Álvarez, Ó. (2014). Non-hegemonic masculinity against gender violence. Procedia-Social and Behavioral Sciences, 161, 48-55.

Frisina, S. (2018). Gender on Jersey Shore (2009-2012): An observation of normative and non-normative performances of masculinity and femininity. Graduate school, Mount Saint Vincent University.

Fulu, E. \& Miedema, S. (2015). Violence against women: globalizing the integrated ecological model. Violence against women, 21(12), 1431-1455.

Gorman-Murray, A. \& Hopkins, P. (2014). Masculinities and Place. England, Ashgate Publishing Limited.

Guedes, A., Bott, S., Garcia-Moreno, C. \& Colombini, M. (2016). Bridging the gaps: a global review of 
intersections of violence against women and violence against children. Global health action, 9(1), 31516.

Howson, R. (2006). Challenging Hegemonic Masculinity. Routledge, USA

Jewkes R., \& Morrell R. (2012). Sexuality and the Limits of Agency among South African Teenage Women: Theorising Femininities and Their Connections to HIV Risk Practices. Social Science \& Medicine.

Jewkes, R., Flood, M. \& Lang, J. (2015). From work with men and boys to changes of social norms and reduction of inequities in gender relations: a conceptual shift in prevention of violence against women and girls. The Lancet.

Kennedy, L. (2016). "He Must Learn What Being a Man is All About”: Negotiating the Male Code at the Louisiana State Penitentiary. Deviant Behavior, 37(2), 151-166.

Kimani, E. \& Kombo, K. (2010). Challenges Facing Nuclear Families With Absent Fathers in Gatundu North District. Central Kenya, 10(2), 2010.

Kimuna, S. R. \& Djamba, Y. K. (2008). Gender based violence: Correlates of physical and sexual wife abuse in Kenya. Journal of family violence, 23(5), 333-342.

Leshota P. (2012) 'Under the Spell of Discrete Islands of Consciousness: My Journey with Masculinities in the Context of HIV and AIDS', in Chitando, E and Chirongoma. S (eds), Redemptive Masculinities: Men, HIV and Religion 149- 70.

Mankowski, E. S. \& Maton, K. I. (2010). A community psychology of men and masculinity: Historical and conceptual review. American Journal of Community Psychology, 45(1-2), 73-86.

Mansley, E.A. (2009). Intimate Partner Violence; Race, Social Class and Masculinity. USA, LFB Scholarly Publishing LLC.

Meda, S. G. (2013). Single mothers of Nairobi: Rural-urban migration and the transformation of gender roles and family relations in Kenya. Urban People, 15(2), 279-307.

Morel-Seytoux, S., Liveoak, C., Mwansa, A., Prieto, D. \& Thompson, J. (2010). USAID/Zambia GBV Programming Evaluation. Washington, DC, DevTech Systems.

Morrell, R. (Ed.). (2001). Changing men in southern Africa. London. Zed books.

Muthoni, K., \& Makana, F. (2015, September 15). Revealed: Secrets behind divorce cases in Kenya. The Standard. Retrieved from https://www.standardmedia.co.ke/article/2000176354/revealed-secrets-behind-divorcecases-in-kenya (Accessed on 25th March 2018)

Muñoz-Boudet, A. M., Petesch, P. \& Turk, C. (2013). On norms and agency: Conversations about gender equality with women and men in 20 countries. The World Bank.

Mwakio, C. W. (2015). The prevalence of depression and intimate partner violence against pregnant women attending antenatal clinic at Kenyatta National Hospital. Graduate school, the University of Nairobi).

NGEC. (2016). Gender-Based Violence in Kenya: The Economic Burden on Survivors. Nairobi. NGEC

Oheneba-Sakyi, Y. \& Takyi, B. K. (2006). African Families at the turn of the $21^{\text {st }}$ Century. West Port, USA. Praeger Publishers.

Orodho, A. J. (2003). Essentials of Educational and Social Science Research Methods. Nairobi. Mazola Publishers.

Oyediran, K. A. \& Isiugo-Abanihe, U. C. (2005). Perceptions of Nigerian women on domestic violence: Evidence from 2003 Nigeria Demographic and Health Survey. African journal of reproductive health, 38-53.

Roman, N. V. \& Frantz, J. M. (2013). The prevalence of intimate partner violence in the family: a systematic review of the implications for adolescents in Africa. Family practice, 30(3), 256-265.

Stevenson, B. \& Wolfers, J. (2007). Marriage and divorce: Changes and their driving forces. Journal of Economic perspectives, 21(2), 27-52.

Sweeney, B. N. (2014). Masculine status, sexual performance, and the sexual stigmatization of women. Symbolic Interaction, 37(3), 369-390.

United Nations. (2018). World Drug Report. United Nations Publications, New York

Van Klinken, A. (2016). Transforming masculinities in African Christianity: gender controversies in times of AIDS. UK. Routledge.

Van Klinken, A. S. \& Smit, P. B. (2013). Jesus Traditions and Masculinities in World Christianity. Exchange, 42(1), 1-15.

Wedgewood, N. (2009). Connell's Theory of Masculinity - its origin and influences on the study of gender. Journal of Gender Studies. United Kingdom. Routledge

Western, D. (2013). Gender-Based Violence and Depression in Women; A Feminist Group Work Response. Springer, New York

World Health Organisation. (2018). Global Health Observatory (GHO) data. WHO, Geneva 